\title{
Estrogen and Progesterone hormone receptor expression in oral cavity cancer
}

\author{
Martin Grimm ${ }^{1}$, Thorsten Biegner ${ }^{2}$, Peter Teriete ${ }^{3}$, Sebastian Hoefert ${ }^{1}$, Michael Krimmel ${ }^{1}$, Adelheid Munz ${ }^{1}$, \\ Siegmar Reinert ${ }^{1}$
}

\footnotetext{
${ }^{1}$ MD, DDS, PhD. Department of Oral and Maxillofacial Surgery, University Hospital Tuebingen, Osianderstrasse 2-8, 72076 Tuebingen, Germany

${ }^{2}$ Department of Pathology, University Hospital Tuebingen, Liebermeisterstrasse 8, 72076 Tuebingen, Germany

${ }^{3}$ Cancer Research Center, Sanford-Burnham Medical Research Institute, 10901 North Torrey Pines Road, La Jolla, CA 92037, USA
}

Correspondence:

Department of Oral and Maxillofacial Surgery

University Hospital Tuebingen

Osianderstrasse 2-8, 72076

Tuebingen, Germany

dr.dr.martingrimm@googlemail.com

\author{
Grimm M, Biegner T, Teriete P, Hoefert S, Krimmel M, Munz A, Reinert \\ $\mathrm{S}$. Estrogen and Progesterone hormone receptor expression in oral cavity \\ cancer. Med Oral Patol Oral Cir Bucal. 2016 Sep 1;21 (5):e554-8. \\ http://www.medicinaoral.com/medoralfree01/v21i5/medoralv21i5p554.pdf

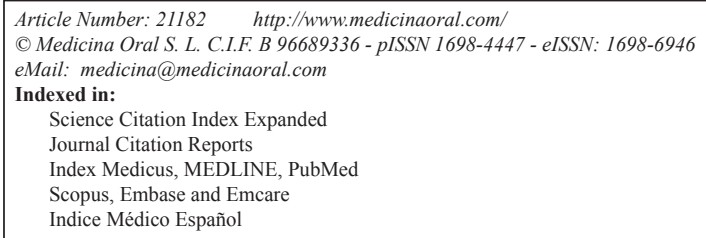

\begin{abstract}
Background: Recent studies have shown an increase in the incidence of oral squamous cell carcinoma (OSCC) in younger patients. The hypothesis that tumors could be hormonally induced during pregnancy or in young female patients without the well-known risk factors alcohol or tobacco abuse seems to be plausible.

Material and Methods: Estrogen Receptor alpha (ER $\alpha$ ) and Progesterone Receptor (PR) expression were analyzed in normal oral mucosa $(n=5)$, oral precursor lesions (simple hyperplasia, $n=11$; squamous intraepithelial neoplasia, SIN I-III, $\mathrm{n}=35)$, and OSCC specimen. OSCCs were stratified in a young female $(\mathrm{n}=7)$ study cohort and older patients $(n=46)$. In the young female study cohort three patients $(n=3 / 7)$ developed OSCC during or shortly after pregnancy. Breast cancer tissues were used as positive control for ER $\alpha$ and PR expression.

Results: ER $\alpha$ expression was found in four oral precursor lesions (squamous intraepithelial neoplasia, SIN I-III, $\mathrm{n}=4 / 35,11 \%)$ and in five OSCC specimen $(\mathrm{n}=5 / 46,11 \%)$. The five ER $\alpha$ positive OSCC samples were older male patients. All patients within the young female study cohort were negatively stained for both ER $\alpha$ and PR.

Conclusions: ER expression could be regarded as a seldom risk factor for OSCC. PR expression seems to be not relevant for the development of OSCC.
\end{abstract}

Key words: Oral squamous cell carcinoma, estrogen receptor, progesterone receptor, hormone receptor. 


\section{Introduction}

Oral squamous cell carcinoma (OSCC) is typically regarded to be a disease that predominantly affects older males $(1,2)$. Intriguingly, recent studies have shown an increase in the incidence of OSCC in young female patients without the well-known causes of OSCC like alcohol and tobacco abuse (2-4). The etiology and pathogenesis of oral cavity cancer in young female patients could be different from those occurring in older patients $(3,5)$. Pregnancy has been shown to be associated with OSCC but there is a paucity of data regarding this etiology as these studies are primarily case reports discussing the challenges that clinicians face in administering treatment that is of maximal benefit to the patient and minimal risk to the fetus $(4,6-10)$.

The hypothesis that tumors could be hormonally induced during pregnancy or in young female patients without the well-known risk factors seems to be plausible. However, it has not yet been determined whether or not a biological predisposition to OSCC exists. In the context of oral cavity carcinogenesis, studies have been shown that hormone receptors, like Estrogen Receptor (ER) and Progesterone Receptor (PR) expression could be regarded as a biological predisposition factor for OSCC (11-15).

Therefore, in our study we compare a series of OSCCs, which were stratified in a young $(<45$ years (16)) female study cohort and older OSCC patients. In the young female OSCC study cohort three patients developed OSCC during or shortly after pregnancy.

Analysis of the mechanistic basis in OSCC development in the context of a multistep carcinogenetic process through morphologically and clinically detectable precancerous stages (17) may harbour the availability of molecular tools to selectively and experimentally manipulate this multistep process. Therefore, ER and PR expression has been additionally analyzed in squamous intraepithelial neoplasia (SIN) lesions.

\section{Material and Methods}

- Patients and Tumor Specimen

The records of healthy individuals (normal oral mucosal tissues, $\mathrm{n}=5$ ), patients with oral precursor lesions (simple hyperplasia, $\mathrm{n}=11$; squamous intraepithelial neoplasia SIN I, n=5; SIN II, n=9; SIN III, severe dysplasia, $\mathrm{n}=10$; SIN III, carcinoma in situ, $\mathrm{n}=11$ ), and patients with invasive OSCC were retrospectively assessed from January 2009 to November 2014. OSCCs were stratified in a young $(<45$ years $(16))$ female $(\mathrm{n}=7$, Table 1$)$ study cohort and older patients ( $n=46$, Table 2) (18). In the young female study cohort three patients $(n=3 / 7)$ developed OSCC during or shortly after pregnancy. The diagnosis of normal oral mucosal tissues, precursor lesions, and invasive squamous cell carcinoma was confirmed by the department of Pathology, Uni-
Table 1. Clinicopathological characteristics of 7 young female patients with OSCC.

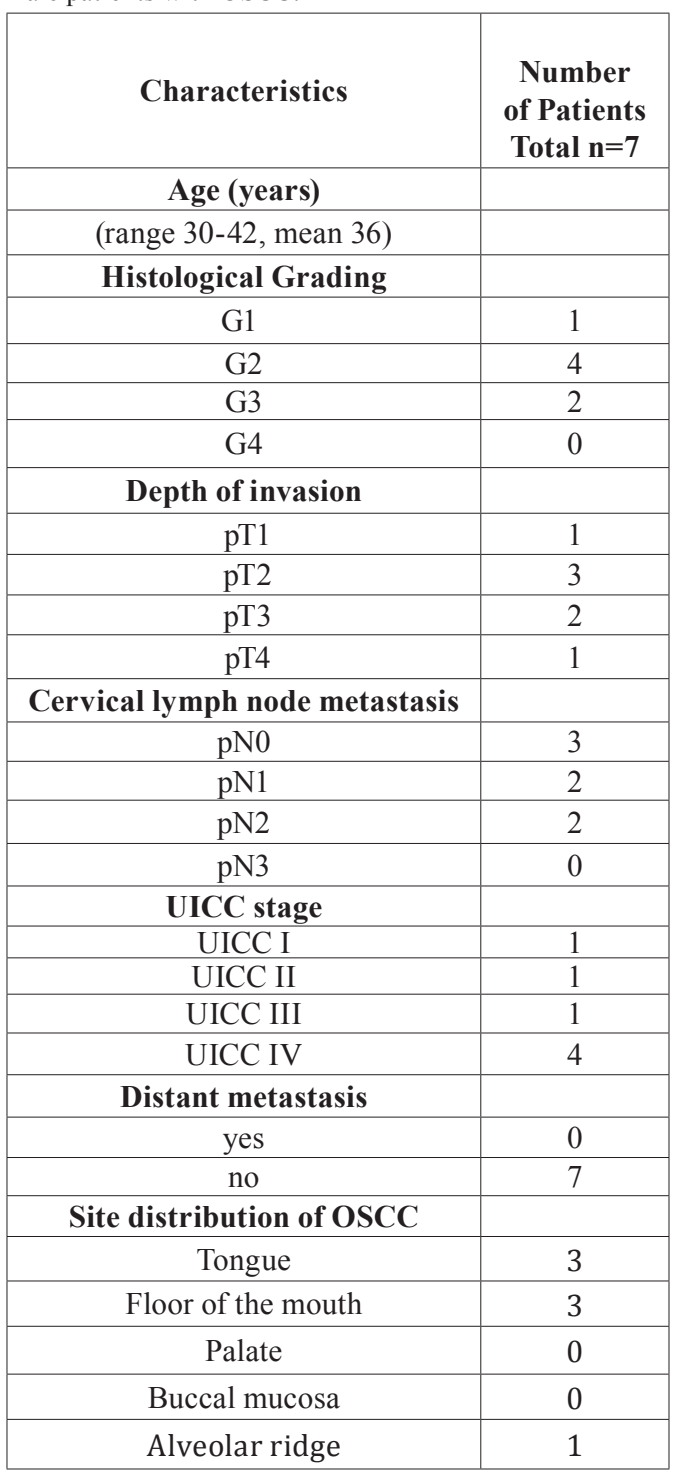

versity Hospital Tuebingen. The material was archival formalin-fixed, paraffin-embedded tissue from routine histopathological work-ups. Both OSCC study cohorts were negatively assessed for human papillomavirus (HPV) in routine analysis by using fluorescence in-situ hybridization (FISH) testing. The material has been stored with permission of the local ethics committee of the University Hospital Tuebingen (approval number: 562-2013BO2), after informed consent obtained from the patients prior to surgical resection. Tumor blocks of paraffin-embedded tissue were selected by experienced pathologists, based on routine H\&E stained sections. Sections from all available tissues underwent histopathological assessment, blinded to the prior histopathology report. Serial tissue sections $(2 \mu \mathrm{m}$ thickness) were cut from formalin-fixed paraffin-embedded (FFPE) blocks on a microtome and mounted from warm 
Table 2. Clinicopathological characteristics of 46 patients with OSCC.

\begin{tabular}{|c|c|}
\hline Characteristics & $\begin{array}{c}\text { Number of Patients } \\
\text { Total } n=46\end{array}$ \\
\hline \multicolumn{2}{|l|}{ Age (years) } \\
\hline \multicolumn{2}{|c|}{ (range $47-87$, mean 65 ) } \\
\hline \multicolumn{2}{|c|}{ Gender } \\
\hline Male & 26 \\
\hline Female & 20 \\
\hline \multicolumn{2}{|l|}{ Histological Grading } \\
\hline G1 & 6 \\
\hline $\mathrm{G} 2$ & 29 \\
\hline G3 & 10 \\
\hline G4 & 1 \\
\hline \multicolumn{2}{|l|}{ Depth of invasion } \\
\hline $\mathrm{pT} 1$ & 12 \\
\hline pT2 & 11 \\
\hline pT3 & 7 \\
\hline pT4 & 16 \\
\hline \multicolumn{2}{|c|}{ Cervical lymph node metastasis } \\
\hline $\mathrm{pN} 0$ & 29 \\
\hline pN1 & 4 \\
\hline pN2 & 11 \\
\hline $\mathrm{pN} 3$ & 2 \\
\hline \multicolumn{2}{|l|}{ UICC stage } \\
\hline UICC I & 9 \\
\hline UICC II & 7 \\
\hline UICC III & 6 \\
\hline UICC IV & 24 \\
\hline \multicolumn{2}{|l|}{ Distant metastasis } \\
\hline yes & 2 \\
\hline no & 44 \\
\hline \multicolumn{2}{|c|}{ Site distribution of OSCC } \\
\hline Tongue & 12 \\
\hline Floor of the mouth & 20 \\
\hline Palate & 6 \\
\hline Buccal mucosa & 1 \\
\hline Alveolar ridge & 7 \\
\hline
\end{tabular}

water onto adhesive microscope slides. First, we assessed H\&E stained sections from each tissue section to differentiate between normal tissue, precursor lesions, tumor cell areas, stromal areas, and infiltrating immune cells. Breast cancer tissues were used as a representative positive control. Oral precursor lesions were classified according to WHO criteria (17). Tumor staging was performed according to the $7^{\text {th }}$ edition of the TNM staging system by the UICC/ AJCC of 2010. Grading of OSCC was defined according to WHO criteria.

- Staining procedure and quantification of immunohistochemistry

We stained for Estrogen Receptor alpha (ER $\alpha$, Dako Cytomation, Hamburg, Germany, rabbit mAb, Code M3643, Clone EP1, dilution 1:50), Progesterone Receptor (PR, Dako Cytomation, mouse mAb, Code M3569, Clone PgR 636, dilution 1:50), and mouse/rabbit isotype controls (BD Pharmingen, Heidelberg, Germany) in tissue sections. Staining was performed on serial sections of $2 \mu \mathrm{m}$ thickness, which were deparaffinized in xylene and ethanol and rehydrated in water. Heat induced epitope retrieval (HIER) was performed with either citrate buffer $\mathrm{pH} 6.0$ (Dako, Hamburg, Germany) or EDTA buffer pH 9.0. Endogenous peroxidase activity was quenched with $0.3 \%$ hydrogen peroxide. Endogenous biotin activity was blocked using the avidin/ biotin blocking kit (Vector Laboratories, Burlingame, CA, USA). After incubation with the primary or rabbit control antibody (BD Pharmingen, Heidelberg, Germany (19) the Dako LSAB2 peroxidase System (Dako, Hamburg) was used. Slides were subsequently incubated for 3-5 minutes in DAB (3,3'-diaminobenzidine, Biogenex) counterstained with haemalaun and mounted with Glycergel (Dako).

Five representative high power fields $(1 \mathrm{HPF}=0.237$ $\mathrm{mm}^{2}$, original magnification: $\mathrm{x} 200$-fold) were analyzed. The extent of the staining, defined as the percentage of positive staining areas of tumor cells in relation to the whole tissue area, was semi-quantitatively scored. A positive result was defined as nuclear staining in $\geq 1 \%$ of tumor cells (20). Two observers blinded to the diagnosis performed scoring on identical sections marked by circling with a water-resistant pencil and finally with diamond-tipped pencil on the opposite side of the microscopic slide. Pictures were analyzed using a Canon camera (Krefeld, Germany). The photographed images were imported into the Microsoft Office Picture Manager.

- Statistical analysis

Statistical analysis was performed with MedCalc Software, Version 15.8 (Mariakerke, Belgium). Descriptive statistics were generated according to case-control status.

\section{Results}

- Expression of ER $\alpha$ and PR in normal mucosa, oral precursor lesions and OSCC

Breast cancer tissues were used as a representative positive control for studying ER $\alpha$ and PR expression (Fig. 1). ER $\alpha$ expression was not found in normal oral mu$\operatorname{cosa}(n=0 / 5)$ and simple hyperplasia $(n=0 / 11)$ but in four oral precursor lesions (squamous intraepithelial neoplasia, SIN I-III, $\mathrm{n}=4 / 35,11 \%$ ) and in five OSCC specimen $(\mathrm{n}=5 / 46,11 \%$, Fig. 2). Positive ER $\alpha$ expression was only found in the older-aged OSCC study cohort. The five positive samples were older male (age: 54-73 years) patients (no female). All patients within the young female study cohort ( $\mathrm{n}=7$, including the three OSCC patients, who developed the tumor during or shortly after pregnancy) were negatively stained for ER $\alpha$.

PR expression was not found in normal oral mucosa $(\mathrm{n}=0 / 5)$, oral precursor lesions (simple hyperplasia, $\mathrm{n}=0 / 11$; squamous intraepithelial neoplasia, SIN I-III, $\mathrm{n}=0 / 35$ ), and OSCC specimen of both study cohorts (older-aged OSCC patients, $\mathrm{n}=0 / 46$; young female OSCC patients $n=0 / 7$ ). 


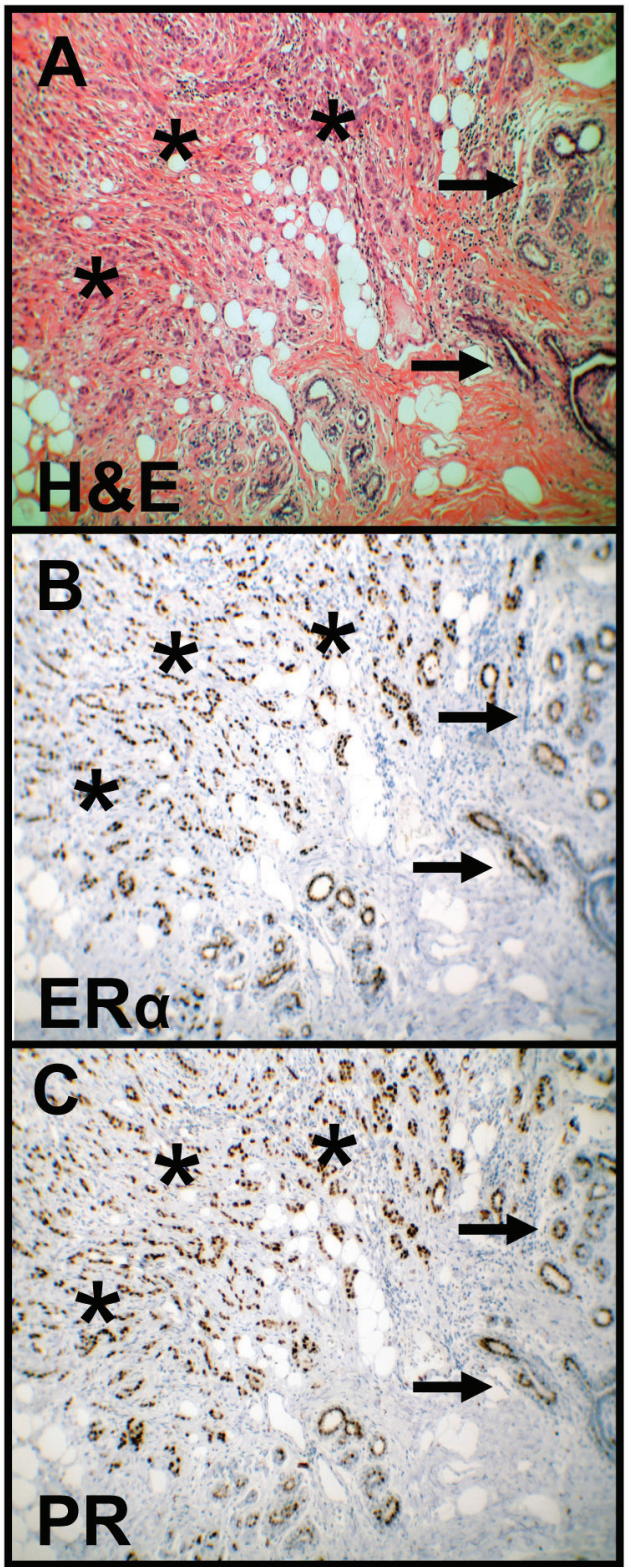

Fig. 1. HE staining and immunohistochemical staining of ER $\alpha$ and PR in breast cancer. HE staining (A) shows tumor cells (asterisks) and normal mammary gland tissue (arrows). Immunohistochemical staining shows representative images of positive $\mathrm{ER} \alpha$ (B) and PR (C) expression in breast cancer as a positive control (asterisks). Brown chromogen color (3,3'-Diaminobenzidine) indicates positive nuclear staining, the blue color shows the nuclear counterstaining by hematoxylin (original magnification: x100-fold). HE, Haematoxylin and eosin; ER $\alpha$, Estrogen Receptor alpha; PR, Progesterone Receptor.

\section{Discussion}

In-vitro studies have shown ER $\alpha$ expression in OSCC cell lines and tumors. The treatment with tamoxifen significantly inhibits OSCC cell proliferation and invasion $(14,15,21-23)$. Therefore, the usage of tamoxifen for targeted therapies may be useful for hormonally active

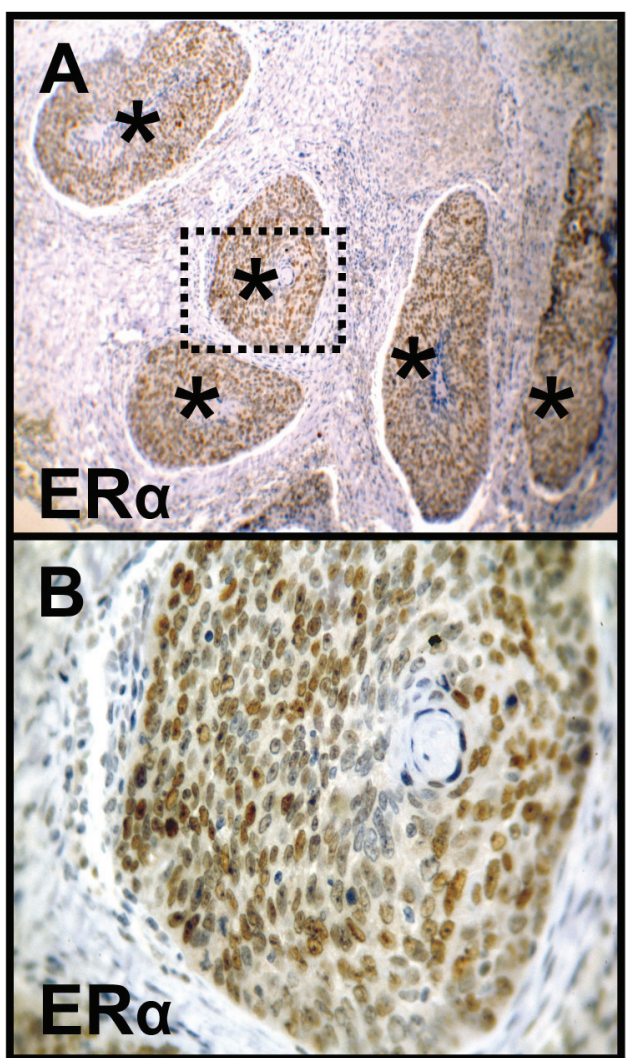

Fig. 2. Immunohistochemical staining of $E R \alpha$ in OSCC. Immunohistochemical staining shows representative images of positive ER $\alpha$ expression (A, B) in OSCC (asterisks). Brown chromogen color (3,3'-Diaminobenzidine) indicates positive nuclear staining, the blue color shows the nuclear counterstaining by hematoxylin. The square box demonstrates the area of interest (original magnification: x100-fold, upper panel, A), which is also shown in larger magnification (x400-fold, lower panel, B). ER $\alpha$, Estrogen Receptor alpha; OSCC, oral squamous cell carcinoma.

OSCCs. In our study, we analyzed the ER $\alpha$ subunit as the alpha subunit plays a predominant role in the promotion of cell growth and survival (24). A study of 24 OSCC specimens demonstrated that the frequency of ER $\alpha$ expression was $50 \%$ (15). Moreover, a previous study by Chang et al. (14) showed that ER $\alpha$ immunoreactivity was observed in $43 \%$ of malignant lesions, whereas none of benign lesions showed ER $\alpha$ immunoreactivity. In our survey, by using well established monoclonal antibodies we detected $11 \%$ positive OSCC samples, which is much lower than the reported prevalence in the current literature but $11 \%$ positive SIN lesions that hasn't been reported as yet.

The activation status of ER $\alpha$ and the regulatory mechanism of ER $\alpha$ activation in OSCC cells are mostly unknown (14). The results published by Chang et al. (14) suggest that ER $\alpha$ activity can be enhanced by focal adhesion kinase (FAK)/Protein kinase B (AKT) signalling, which is critical for promoting cell growth in 
OSCC cell lines. Moreover, a cross-talk between ER and epidermal growth factor receptor (EGFR) in head and neck squamous cell carcinoma cell lines has been reported (25).

Intriguingly, positive $\mathrm{ER} \alpha$ expression was only found in the older-aged OSCC study cohort. The five positive samples were older male patients (no female). All patients within the young female study cohort (including the three OSCC patients, who developed the tumor during or shortly after pregnancy) were negatively stained for both ER $\alpha$ and PR. Therefore, sexual hormone receptor expression could not be regarded as a risk factor for young female OSCC patients or pregnancy. The reason for ER $\alpha$ expression in older male patients remains unclear.

\section{Conclusions}

Based on the results of the present study sexual hormone receptor expression is not associated with young OSCC female patients or pregnancy. ER expression could be regarded as a seldom risk factor for OSCC, whereas PR expression seems to be not relevant for the development of OSCC.

\section{- Abbreviations}

SIN, squamous intraepithelial neoplasia; OSCC, oral squamous cell carcinoma; ER $\alpha$, Estrogen Receptor alpha; PR, Progesterone Receptor.

\section{References}

1. Grimm M. Prognostic value of clinicopathological parameters and outcome in 484 patients with oral squamous cell carcinoma: microvascular invasion $(\mathrm{V}+)$ is an independent prognostic factor for OSCC. Clinical \& translational oncology: official publication of the Federation of Spanish Oncology Societies and of the National Cancer Institute of Mexico. 2012;14:870-80.

2. Franca DC, Monti LM, de Castro AL, Soubhia AM, Volpato LE, de Aguiar SM, et al. Unusual presentation of oral squamous cell carcinoma in a young woman. Sultan Qaboos Univ Med J. 2012;12:22831.

3. Goepfert RP, Kezirian EJ, Wang SJ. Oral tongue squamous cell carcinoma in young women: a matched comparison-do outcomes justify treatment intensity?. ISRN Otolaryngol. 2014;2014:529395.

4. Eliassen AM, Hauff SJ, Tang AL, Thomas DH, McHugh JB, Walline HM, et al. Head and neck squamous cell carcinoma in pregnant women. Head Neck. 2013;35:335-42.

5. Hirota SK, Braga FP, Penha SS, Sugaya NN, Migliari DA. Risk factors for oral squamous cell carcinoma in young and older Brazilian patients: a comparative analysis. Med Oral Patol Oral Cir Bucal. 2008;13:E227-31.

6. Cheung EJ, Wagner H Jr, Botti JJ, Fedok F, Goldenberg D. Advanced oral tongue cancer in a 22 -year-old pregnant woman. Ann Otol Rhinol Laryngol. 2009;118:21-6.

7. Shen S, Xu L, Yin X, Fan X, Zhang C, Hze-Khoong EP, et al. A case of a squamous cell carcinoma of the tongue during pregnancy. Oral Oncol. 2011;47:924-6.

8. Dumper J, Kerr P. Recurrent squamous cell carcinoma of the tongue in pregnancy. J Otolaryngol. 2005;34:242-3.

9. Lloyd CJ, Paley MD, Penfold CN, Varadarajan V, Tehan B, Gollins SW. Microvascular free tissue transfer in the management of squamous cell carcinoma of the tongue during pregnancy. Br J Oral Maxillofac Surg. 2003;41:109-11.
10. Cudney N, Ochs MW, Johnson J, Roccia W, Collins BM, Costello BJ. A unique presentation of a squamous cell carcinoma in a pregnant patient. Quintessence Int. 2010;41:581-3.

11. Colella G, Izzo G, Carinci F, Campisi G, Lo Muzio L, D’Amato S, et al. Expression of sexual hormones receptors in oral squamous cell carcinoma. Int J Immunopathol Pharmacol. 2011;24:129-32.

12. Marocchio LS, Giudice F, Correa L, Pinto Junior DS, de Sousa SO. Oestrogens and androgen receptors in oral squamous cell carcinoma. Acta Odontol Scand. 2013;71:1513-9.

13. Nehse G, Tunn S. Androgen and progesterone receptors in oral carcinoma. J Craniomaxillofac Surg. 1994;22:114-9.

14. Chang YL, Hsu YK, Wu TF, Huang CM, Liou LY, Chiu YW, et al. Regulation of estrogen receptor alpha function in oral squamous cell carcinoma cells by FAK signaling. Endocr Relat Cancer. 2014;21:555-65.

15. Lukits J, Remenár E, Rásó E, Ladányi A, Kásler M, Tímár J. Molecular identification, expression and prognostic role of estrogenand progesterone receptors in head and neck cancer. Int J Oncol. 2007;30:155-60.

16. Lee CC, Ho HC, Chen HL, Hsiao SH, Hwang JH, Hung SK. Squamous cell carcinoma of the oral tongue in young patients: a matched-pair analysis. Acta Otolaryngol. 2007;127:1214-7.

17. Driemel O, Hertel K, Reichert TE, Kosmehl H. Current classification of precursor lesions of oral squamous cell carcinoma principles of the WHO classification 2005. Mund Kiefer Gesichtschir. 2006;10:89-93.

18. Grimm M, Calgéer B, Teriete P, Biegner T, Munz A, Reinert S. Targeting thiamine-dependent enzymes for metabolic therapies in oral squamous cell carcinoma? Clin Transl Oncol. 2016;18:196-205. 19. Grimm M, Cetindis M, Lehmann M, Biegner T, Munz A, Teriete $\mathrm{P}$, et al. Association of cancer metabolism-related proteins with oral carcinogenesis - indications for chemoprevention and metabolic sensitizing of oral squamous cell carcinoma? J Transl Med. 2014;12:208.

20. Diaz LK, Sneige N. Estrogen receptor analysis for breast cancer: current issues and keys to increasing testing accuracy. Adv Anat Pathol. 2005;12:10-9.

21. Ishida H, Wada K, Masuda T, Okura M, Kohama K, Sano Y, et al. Critical role of estrogen receptor on anoikis and invasion of squamous cell carcinoma. Cancer Sci. 2007:98:636-43.

22. Kim MJ, Lee JH, Kim YK, Myoung H, Yun PY. The role of tamoxifen in combination with cisplatin on oral squamous cell carcinoma cell lines. Cancer Lett. 2007;245:284-92.

23. Ku TK, Crowe DL. Coactivator-mediated estrogen response in human squamous cell carcinoma lines. J Endocrinol. 2007;193:14755 .

24. Thomas C, Gustafsson JA. The different roles of ER subtypes in cancer biology and therapy. Nat Rev Cancer. 2011;11:597-608.

25. Egloff AM, Rothstein ME, Seethala R, Siegfried JM, Grandis JR, Stabile LP. Cross-talk between estrogen receptor and epidermal growth factor receptor in head and neck squamous cell carcinoma. Clin Cancer Res. 2009;15:6529-40.

\section{Conflict of Interest}

The authors have declared that no conflict of interest exist. 